\title{
Percepção dos pais diante do diagnóstico e da abordagem fisioterapêutica de crianças com paralisia cerebral
}

\author{
Parents' perception facing the diagnostic and physiotherapeutic approach for \\ children with cerebral palsy
}

Clarissa Niederauer Leote da Silva Pedroso ${ }^{1}$, Mauro Antônio Félix ${ }^{2}$

RESUMO

Objetivo: Investigar qual a percepção dos pais de crianças com paralisia cerebral (PC) diante do diagnóstico e da abordagem fisioterapêutica.

Materiais e Métodos: Foi realizado um estudo do tipo observacional exploratório de casos. A pesquisa foi desenvolvida em uma instituição de reabilitação física e inclusão social da cidade de Canoas, Rio Grande do Sul, entre os meses de janeiro e fevereiro de 2012. Foram abordados dez pais, escolhidos por conveniência, cujos filhos recebem atendimento no setor de fisioterapia da instituição. Os dados coletados foram organizados e categorizados, possibilitando a interpretação segundo a análise de conteúdo de Bardin.

Resultados: Participaram da pesquisa nove mães e um pai, com idades média de 35 anos e 4 meses. Verificou-se que os pais mudaram a sua percepção de diagnóstico em relação ao instante em que ele foi noticiado e ao momento atual, passando de incertezas e de pouco entendimento para uma fase de aceitação e esclarecimento. Houve demora na confirmação do diagnóstico e no encaminhamento para a fisioterapia. A abordagem fisioterapêutica foi vista como algo indispensável para a evolução da criança, sendo percebidos progressos no quadro do filho após o início do tratamento. Os participantes afirmaram receber e realizar as orientações fornecidas pelo fisioterapeuta.

Conclusão: A percepção dos pais em relação ao diagnóstico é moldada na medida em que a criança inicia o tratamento e recebe acompanhamento profissional, somado ao próprio desenvolvimento dela. Quanto à percepção a respeito da fisioterapia observou-se que no momento em que os pais receberam o encaminhamento para o tratamento fisioterapêutico eles demonstraram expectativas mais positivas para a vida do filho, principalmente para melhorar suas condições motoras.

Palavras-chave: fisioterapia; paralisia cerebral; percepção; pais.

\section{ABSTRACT}

Objective: To investigate parent's perception over their children with cerebral palsy (CP) facing the diagnosis and physiotherapeutic approach.

Materials and Methods: An exploratory observational study of cases was performed. The research was conducted at an institution of physical rehabilitation and social inclusion from Canoas city, Rio Grande do Sul, between the months of January and February 2012. Ten parents have been included, chosen by convenience, whose children receive care at the Institution's physical therapy unit. The data collected were organized and categorized, allowing the interpretation according to the content analysis of Bardin.

Results: Nine mothers and one father have participated in this research, with a mean age of 35 years and 4 months. It was found that the parents changed their perception over the diagnosis in relation to the moment it was reported compared to the current time, varying from uncertainties and little understanding to a stage of acceptance and enlightenment. There was a delay in the diagnosis confirmation, as well as in the referral to physiotherapy. The physiotherapeutic approach was seen as an essential step for the child's development and it was identified progress after the start of the treatment. Participants declared to receive and to make the orientations provided by the physiotherapist.

Conclusions: The parents' perception regarding the diagnosis is formed as the child starts treatment and receives professional support, added to her own development. Regarding the perception about the physical therapy, it was observed that when parents received a referral for physical therapy, they showed more positive expectations over their child's life, mainly regarding motor condition improvements.

Keywords: physical therapy specialty; cerebral palsy; perception; parents.

\footnotetext{
${ }^{1}$ Fisioterapeuta. Mestranda em Saúde Coletiva pela Universidade do Vale do Rio dos Sinos (UNISINOS).

${ }^{2}$ Fisioterapeuta. Mestre em Antropologia Social pela Universidade Federal do Rio Grande do Sul (UFRGS).
} 


\section{INTRODUÇÃO}

A paralisia cerebral (PC) é uma disfunção neuromotora, de caráter não progressivo, decorrente de uma lesão no cérebro em processo de maturação. Pode acometer uma ou várias regiões cerebrais em específico, gerando comprometimentos que afetam a postura, o movimento e até mesmo as funções cognitivas dependendo da lesão e da idade da criança $^{1,2}$. A incidência de paralisia cerebral está em torno de 2:1000 nascimentos nos países desenvolvidos, uma frequência que não tem se modificado nos últimos anos. No Brasil, um país em desenvolvimento, não há dados conclusivos a respeito, mas estima-se que a cada 1000 crianças que nascem, sete possuem $\mathrm{PC}^{1,3}$.

Além do déficit motor e da alteração de tônus, o indivíduo com paralisia cerebral geralmente apresenta alguma patologia associada, como acometimento cognitivo, distúrbios visuais, epilepsia, distúrbio da fala, perda auditiva, complicações respiratórias e gastrointestinais ${ }^{4}$. Quanto ao diagnóstico de paralisia cerebral, este é predominantemente clínico e tem como fator principal o evidente atraso no desenvolvimento motor. Quando esse fator é observado em uma criança e está associado com reflexos primitivos persistentes e alteração de tônus muscular, a suspeita de PC deve ser considerada $^{5}$.

Com base nesses aspectos se observa a relevância de conhecer a forma com que os pais de uma criança com o diagnóstico de paralisia cerebral enfrentam tal situação. Esses pais terão de abandonar as fantasias do filho idealizado e defrontar-se com os conflitos presentes nessa nova realidade ${ }^{6,7}$. Após o estabelecimento do diagnóstico, os pais devem ser informados sobre a patologia de seu filho e das prováveis limitações ${ }^{8}$. O fisioterapeuta é um dos profissionais responsáveis por isso, pois manterá um contato contínuo com a criança e sua família. O tratamento fisioterapêutico será direcionado de acordo com as etapas do desenvolvimento neuropsicomotor normal, priorizando sempre a funcionalidade da criança $^{9,10}$. Juntamente a isso, o fisioterapeuta também deve transmitir aos cuidadores as informações necessárias sobre os cuidados domésticos diários com a criança, visando a tornar a vivência no ambiente familiar uma extensão do tratamento ${ }^{8}$.

Dessa forma, a presente pesquisa traz como objetivo geral investigar a percepção dos pais em relação ao diagnóstico e a abordagem fisioterapêutica do filho com paralisia cerebral, uma vez que o entendimento adequado da doença, das limitações funcionais e das potencialidades da criança são questões fundamentais para uma maior colaboração da família no tratamento. Ainda, teve como objetivos específicos verificar qual a percepção dos pais em relação ao diagnóstico do filho e o seu impacto no ambiente familiar; observar qual o entendimento que os pais têm diante da situação do filho e as suas repercussões na vida da criança e da família; e identificar qual é a percepção que os pais possuem em relação ao tratamento fisioterapêutico frente às necessidades de seu filho.

\section{MATERIAIS E MÉTODOS}

Esta pesquisa foi do tipo observacional exploratória de casos, visando a obter dados descritivos mediante contato direto e interativo com o objeto de estudo ${ }^{11}$. A pesquisa foi realizada em uma instituição de reabilitação física e inclusão social situada na cidade de Canoas, no estado do Estado Rio Grande do Sul, entre os meses de janeiro e fevereiro do ano de 2012. Para o objetivo do estudo foram abordados dez pais, escolhidos por conveniência, a partir dos prontuários das crianças com paralisia cerebral que recebem atendimento no setor de fisioterapia da instituição. Foram incluídos no estudo mães e pais que se dispuseram a participar de toda a entrevista e tinham filhos com diagnóstico de paralisia cerebral registrado no prontuário. Na coleta dos dados foi utilizada como instrumento uma entrevista do tipo aberta, semiestruturada, elaborada pelos autores do estudo. A entrevista continha questões referentes ao período gestacional (pré-natal e expectativas do nascimento e parto), diagnóstico da criança (quando e como o recebeu, qual o entendimento, o impacto familiar e o significado atual), limitações e prognóstico (limitações na rotina, potenciais do filho, expectativas para o futuro e convívio social) e ao tratamento fisioterapêutico (encaminhamento para fisioterapia, tempo para procurar o tratamento, por que buscou a terapia, expectativas, participação e relacionamento 
com o fisioterapeuta). Para isso, foi usado um gravador de áudio, a fim de obter as informações por meio da fala individual, transmitindo as representações de cada pai e mãe participante da pesquisa ${ }^{11}$. Também foram colhidas variáveis para a caracterização dos participantes, como: idade, estado civil, escolaridade, situação ocupacional, renda familiar, número de indivíduos na família, convênio de saúde, benefício do governo e quem fica de responsável pela criança. Além disso, dados quanto à classificação do comprometimento motor e uso de dispositivos auxiliares das crianças foram retirados diretamente nos prontuários. Os dados foram coletados dentro da própria instituição. A coleta de dados ocorreu na hora em que a criança estava recebendo atendimento fisioterapêutico. Os pais responderam à entrevista de forma individual e não por casal.

Todas as entrevistas registradas na gravação de áudio foram degravadas na íntegra para posterior análise. Os textos transcritos não sofreram alterações linguísticas, a fim de não eliminar o caráter espontâneo das falas. Com as respostas já transcritas da entrevista foi feito um processo de codificação e categorização. A codificação corresponde a uma transformação dos dados brutos dos textos, que permite atingir uma representação do seu conteúdo. Para isso, seguiram-se as regras de recorte, classificação e agregação. Desse modo, a interpretação dos dados utilizou a análise de conteúdo de Bardin. Para o estudo qualitativo a análise de conteúdo de Bardin leva em consideração a presença ou a ausência de uma dada característica de conteúdo ou de um conjunto de características num determinado fragmento de mensagem ${ }^{12}$. Assim, foram estabelecidas as seguintes categorias: Período Gestacional e Parto; Diagnóstico; Limitações e Prognóstico; Tratamento Fisioterapêutico e Participação no Tratamento (TTO). A partir dessas criaram-se as subcategorias a fim de facilitar posterior codificação.

Atendendo aos preceitos da Resolução 196/96 do Conselho Nacional da Saúde, o presente estudo foi aprovado pelo Comitê de Ética e Pesquisa (CEP) da UNISINOS, sob o parecer número 160/2011. Junto a isso, todos os participantes assinaram o Termo de Consentimento Livre e Esclarecido. Com a intenção de resguardar a identidade dos participantes foram utilizados códigos seguidos da idade.

\section{RESULTADOS E DISCUSSÃO}

Caracterização das mães e do pai

Participaram do estudo nove mães e um pai. As mães apresentaram uma média de idade de 40 anos, sendo a idade mínima observada de 23 anos e a idade máxima de 49 anos. O pai tinha 35 anos de idade. Verificou-se que $50 \%$ dos entrevistados eram casados. Em relação à ocupação dos pais, percebe-se que sete mães participantes pararam de trabalhar depois do nascimento do filho. O pai participante relata não ter deixado o trabalho. Dessa forma, constatou-se que oito (80\%) famílias são mantidas financeiramente pelo homem. Segundo Barbosa et al. ${ }^{13}$, algumas mães vêemse diante da necessidade de deixar o trabalho para atender às demandas de cuidado do filho deficiente. Já com o homem, a cobrança como pai não é tão acirrada. $\mathrm{Na}$ normativa social, o pai deve simplesmente prover o sustento da família ${ }^{14}$.

\section{Caracterização das crianças}

Neste estudo, seis crianças são do sexo masculino e quatro do sexo feminino. A média de idade das crianças é de quatro anos e sete meses, sendo que a idade mínima encontrada foi de um ano e a idade máxima de dez anos. Com relação ao comprometimento motor, sete $(70 \%)$ são consideradas com quadriplegia e todas elas são classificadas como paralisia cerebral do tipo espástica. Já na característica de controle motor é visto que sete $(70 \%)$ crianças possuem controle cervical e seis possuem controle de tronco e cervical. Porém, cinco (50\%) crianças não conseguem realizar a marcha independente, por isso utilizam órteses e cadeira de rodas, sendo que duas dessas também utilizam o andador. As demais crianças usam apenas as órteses como auxílio.

\section{Percepção dos pais diante do diagnóstico}

Observou-se na pesquisa que três mães afirmaram não ter planejado a gravidez. A maioria não se importava com o sexo da criança. Entretanto, todos relataram que esperavam por um filho saudável e 
perfeito:

“(..) a gente esperava um filho perfeito né, não importava se fosse menino ou menina. A gente imaginava uma criança com bastante saúde, normal, como todas as outras crianças" (P1, 48 anos).

Os pais esperam gerar um bebê saudável e que cresça como qualquer outra criança, visto que representa a autoimagem do casal, sendo então, o espelho deles ${ }^{15,16}$. O problema é quando esses mesmos pais repletos de expectativas, metas e idealizações se deparam com a realidade de um filho com o diagnóstico de uma deficiência como a paralisia cerebral ${ }^{7}$. Esse fato está bem representado no seguinte relato:

"Uma coisa é certa, ninguém espera ter um filho deficiente em casa. Ninguém tem essa perspectiva. Tu imagina uma criança que vá caminhar, falar, brincar, correr, que faça tudo aquilo que uma criança normal faz sabe (...)" (P2, 23 anos).

No presente estudo, nove mães realizaram todo o acompanhamento pré-natal pelo SUS. Algumas tiveram problemas de hipertensão arterial, outras apresentavam má formação uterina e as demais afirmaram que estava aparentemente tudo certo com elas e com o bebê. Constatou-se que houve cinco partos normais e cinco cesarianas. Dos partos normais, dois foram feitos com insistência do médico, sem ter indicação. Já as cesarianas, três foram realizadas de última hora, após tentativas de realizar o parto normal, gerando sofrimento fetal. Além disso, verificou-se um total de sete partos prematuros.

Apesar de a maioria das crianças (70\%) consideradas nesta pesquisa necessitarem da permanência por vários dias e até meses na UTI neonatal devido a intercorrências como má formação (20\%), hemorragia vascular cerebral (10\%), prematuridade (60\%), microcefalia (20\%), meningite bacteriana (20\%) e citomegalovírus (10\%), apenas uma mãe participante afirmou ter recebido o diagnóstico de paralisia cerebral ainda no hospital. O restante dos pais diz que seus filhos foram para casa sem confirmação de diagnóstico, somente com a informação de que o filho poderia ter alguma sequela, recebendo o diagnóstico apenas meses depois da alta hospitalar.

Em outro estudo semelhante, realizado por Kempinski ${ }^{17}$, foi visto que $64 \%$ das mães entrevistadas afirmaram receber o diagnóstico por meio de um médico, porém, tardiamente, sendo que só se obteve a confirmação após seis meses de idade ou até mais que um ano de vida.

Segundo Fonseca \& Mariano ${ }^{18}$, os pais se queixam dos médicos que não conversam sobre a saúde do seu filho. Quando um familiar está apreensivo por alguma resposta e questiona o médico, mesmo que exista apenas uma suspeita de diagnóstico, o profissional precisa passar algum tipo de informação. O médico deve conseguir transmitir segurança e tranquilidade para os pais enquanto não se tem o diagnóstico fechado.

Além disso, quatro mães relataram que mesmo sem a confirmação do diagnóstico de seu filho, elas começaram a perceber, com o passar do tempo, que o desenvolvimento da criança não condizia com o considerado saudável, gerando muita angústia diante da incerteza do que estava acontecendo. Baird et al. ${ }^{19}$ ao entrevistarem 180 pais de crianças com PC quanto à percepção deles em relação ao diagnóstico, verificaram que $92,86 \%$ já haviam suspeitado de que "havia algo errado com a criança" antes de receberem diagnóstico.

As mães foram buscar repostas em consultas médicas com o intuito de saber qual a real situação do seu filho:

“(..) Com seis meses eu percebi que ele não era normal porque ele não sentava, não engatinhava, ele se arrastava e minha guriazinha mais velha sentava com essa idade, ela começou a caminhar com um ano e ele não. Então eu levei ele pra consultar pra saber o que ele tinha e o que poderia ser feito (...)" (P3, 34 anos).

Estudos semelhantes mostram relatos de famílias afirmando que à medida que a criança crescia, elas começaram a perceber atrasos em seu desenvolvimento, como a demora em sentar, seguido do engatinhar, andar, falar e, posteriormente, no 
desempenho de habilidades motoras e mentais. Essas constatações eram guiadas muitas vezes pela comparação entre os irmãos ${ }^{20}$.

Após a busca por uma explicação a respeito do quadro que o filho apresenta, deve-se considerar a maneira que os pais reagem diante da confirmação do diagnóstico. Constatou-se na entrevista reações de confusão, desespero, choro, depressão e uma difícil aceitação do filho que é diferente. Uma mãe usou as palavras luto e raiva para descrever o recebimento do diagnóstico:

"Eu fiquei com um misto assim de raiva, de medo e de luto (...). No primeiro momento sentimentos muito negativos de que realmente era o fim" (P4, 39 anos).

Assim, percebe-se que mesmo que os pais notem que existe algo errado com o filho, eles nunca irão imaginar a possibilidade de seu filho estar com uma deficiência. Pode-se dizer que mesmo depois de uma interminável peregrinação dos pais pelos consultórios, o impacto da notícia não é menor ${ }^{21}$. Em contraste, uma das mães, que possui um irmão com PC, afirmou não ter sentido tanto desespero diante do diagnóstico, provavelmente devido a sua convivência familiar:

“(..) Eu já tinha na minha cabeça que 99\% o que ela tinha era paralisia cerebral, por causa do que eu via no meu irmão (...)" (P1, 48 anos).

De fato, assim como foi encontrado em outras pesquisas, evidencia-se que para as mães que tiveram pouco contato e informação sobre o assunto a aceitação demonstrou ser mais lenta e dolorosa, enquanto que o processo era facilitado para aqueles que tiveram maior convivência ${ }^{22}$.

Ao informarem sobre o entendimento quanto ao diagnóstico de paralisia cerebral, confirmou-se que cinco mães já tinham ouvido falar de PC embora não entendessem bem o que significava e duas mães relataram ter uma noção por existir casos na família. Foi possível observar que há uma homogeneidade de pensamento quanto ao fato de a paralisia cerebral ser vista como algo que afeta apenas o sistema motor da criança:

“(...) na hora eu entendi que podia afetar alguma coisa da coordenação motora dele, só não sabia direito como e o que seria (...)" (P5, 37 anos).

Em um estudo proposto por Gração \& Santos ${ }^{8}$, também foi possível perceber que a grande maioria das mães desconhece o conceito de $\mathrm{PC}$ e os que relataram algum conhecimento associaram a lesão cerebral com a ausência de controle motor.

Infelizmente os médicos pouco esclarecem aos familiares a respeito das possibilidades de desenvolvimento da criança, das superações e dificuldades e menos ainda sobre os locais onde os recursos são oferecidos ${ }^{23}$.

Outro fator que deve ser considerado é o impacto que esse diagnóstico causa no ambiente familiar. Os familiares geralmente enfrentam diferentes exigências, alterações no seu cotidiano e readaptações, afetando vários aspectos, como o financeiro, ocupacional, pessoal e a interação familiar $^{10}$. Algumas mães expressaram o sentimento de que a responsabilidade pelo filho ficou mais sob o cuidado dela, sentindo a necessidade de mais apoio por parte do cônjuge:

"Eu fico mais cansada (...). Às vezes eu queria ter alguém pra compartilhar um pouco mais. Eu acho o meu marido meio imparcial pra algumas coisas (...)" (P4, 39 anos).

A família é transformada com a deficiência do filho, mostrando-se inicialmente frágil perante as atividades do dia a dia e a mãe sente a necessidade do apoio familiar como auxílio emocional e prático para convivência e cuidados com o filho deficiente ${ }^{13}$.

Com o passar do tempo espera-se que a maior convivência com o filho leve a um entendimento sobre a paralisia cerebral diferente daquele que fora estabelecido inicialmente. Todos os participantes relataram possuir um melhor esclarecimento da situação do filho, tendo consciência das limitações:

“(...) Hoje eu vejo diferente. Ele tem dificuldades, mas 
tu vê resultados bons. A gente sabe que é uma lesão cerebral e que as sequelas vão sempre existir, que tem limitações, atraso motor e cognitivo, mas aos poucos ele está se desenvolvendo (...)" (P6, 35 anos).

Assim como o estudo de lervolino ${ }^{24}$, ao fazer a comparação dos sentimentos das mães no momento do diagnóstico com os sentimentos atuais percebeu-se que houve uma mudança de sentimentos de incerteza, tristeza, raiva, depressão e não entendimento para sentimentos de aceitação, esperança e compreensão.

Todavia, duas mães participantes deste estudo disseram que seus maridos ainda apresentam dificuldades de aceitação, negando o diagnóstico da criança:

“(...) Pra ele o filho dele é perfeito. Às vezes eu tenho que ser dura com ele e dizer que o filho dele tem paralisia cerebral e que ele tem que entender. (...) Pro meu marido ainda é difícil entender tudo isso" (P2, 23 anos).

Apesar de poucos estudos referirem o impacto do diagnóstico para o pai, alguns autores referem que aparentemente o pai vivencia níveis mais elevados de estresse, utilizando mais frequentemente estratégias de fuga e evitando lidar com a situação ${ }^{10}$. Porém, o pai participante da pesquisa demonstrou ter conseguido aceitar a condição de saúde de sua filha:

“Eu vejo que o que ela tem é uma lesão cerebral e que isso não vai reverter. Pode amenizar as sequelas, mas não tem cura. Nós conseguimos entender que isso faz parte das condições dela" (P7, 35 anos)

Conhecimento dos pais e repercussões na vida da família e da criança

Buscaram-se depoimentos de como os pais enxergam as limitações do filho no dia a dia, assim como as suas potencialidades. Quanto às limitações, todos relataram dificuldades que eles percebem na rotina diária do filho, como: não conseguir comer sozinho, ter restrições alimentares, dependência para fazer a higiene, pegar os brinquedos e se deslocar. Mas a principal limitação vista pelos pais é a dificuldade para caminhar:

"A dificuldade maior que a nossa filha tem é de caminhar, por causa da sequela do lado direito, ela não tem apoio desse lado (...)” (P7, 35 anos).

O estudo realizado por Vieira et al. ${ }^{25}$ mostra que os pais conhecem as limitações e situações críticas enfrentadas durante o dia a dia, sendo as mais percebidas durante 0 desempenho das atividades cotidianas das crianças. Também foi observado que os pais têm como principal queixa as limitações motoras da criança.

No caso das potencialidades da criança, os pais inicialmente tiveram dificuldades em expressá-las, trazendo relatos referentes às atividades e habilidades do filho:

"Ela vai ao banheiro sozinha, consegue ajudar a vestir a roupa, comer sozinha (...)" (P1, 48 anos).

Portanto, assim como os pais percebem as condições restritas do filho, também reconhecem as habilidades que ele tem. Isso é importante porque assim poderão ser criados meios favoráveis de desenvolvimento, beneficiando o tratamento da criança ${ }^{25}$. No que diz respeito ao contexto social da criança, todos os pais anseiam por seu filho poder estar presente no ambiente escolar, o que demonstra que eles conseguem enxergar um potencial no filho. Inclusive, cinco crianças envolvidas no estudo já estão frequentando a escola regular. Quando se discute a inserção social de uma criança com deficiência, considera-se a escola como porta de entrada para isso, já que ela é vista como um dos espaços mais significativos para promover a participação social da criança com $\mathrm{PC}^{26,27}$.

Dessa forma, podemos considerar que as habilidades que a criança trabalha durante as sessões de fisioterapia devem ser úteis dentro da realidade em que ela vive. Nunca se deve ignorar a necessidade de estimular a educação da criança. O fisioterapeuta ao acompanhar o desenvolvimento da criança tem como função estar atento à capacidade dela de participar na escola, procurando trabalhar sua funcionalidade $e$ 
buscando recursos que possibilitem a sua adaptação dentro da sala de aula e demais espaços pedagógicos. Além disso, o profissional deve atuar não somente com questões de acessibilidade e adequações posturais, mas também junto aos professores envolvidos no processo de ensino-aprendizagem da criança com deficiência. A presença do fisioterapeuta na escola pode facilitar o reconhecimento dos professores e demais profissionais da educação das alterações decorrentes da doença e dos potenciais a serem estimulados no aluno. Isso é essencial para que a criança com PC possa realmente usufruir positivamente do sistema de inclusão escolar.

Quanto ao entendimento dos pais relacionado às perspectivas do filho em longo prazo, todos os sujeitos participantes afirmaram que não sabem o que aguardar para o futuro:

"Ela está ótima agora, mas no futuro a gente não sabe. Infelizmente ou felizmente, a gente tem que estar pronto para que aquela evolução maravilhosa dela pare, ou que ela melhore cada vez mais, que é o que a gente espera" (P7, 35 anos).

Percebe-se que há um desejo de que o filho possa melhorar o máximo possível. Existe nos pais o sentimento de esperança:

“Eu tenho certeza que a minha filha vai caminhar. Não tô dizendo, assim, que ela não vai ter nenhuma dificuldade pra caminhar, mas eu acredito que ela vai conseguir" (P8, 41 anos).

De acordo com Miura ${ }^{28}$, independente da explicação que os pais possuem sobre o diagnóstico, eles esperam que o filho melhore. A esperança de cura é um sentimento constante, mesmo que os pais tenham conhecimento da gravidade da doença. É uma forma estratégica para lidar com perdas e mudanças no estilo de vida, que leva a uma diminuição da ansiedade por parte dos familiares ${ }^{28}$.

O tipo de incerteza com o futuro evolui com a idade da criança e com a patologia própria da $\mathrm{PC}$, pois, à medida que aumenta a idade da criança e a sintomatologia se torna mais visível e complexa, assim também se modifica o tipo específico de preocupação com o futuro ${ }^{6}$. Essa constatação pode ser percebida com as mães participantes que já estão com os filhos mais velhos, como por exemplo, neste depoimento de uma mãe com a filha de 9 anos:

"Na verdade eu já não espero muita coisa. Vamos deixar o tempo ir levando e ver o que vai acontecendo. Eu não tenho aquela esperança de que ela vai conseguir atingir tudo porque ela realmente tem bastante dificuldade" (P1, 48 anos).

\section{Percepção dos pais diante da fisioterapia}

Constatou-se que a maioria dos pais relatou ter que ir a mais de um médico até conseguir uma prescrição de tratamento. O encaminhamento para o fisioterapeuta, segundo os pais, foi indicação do médico neurologista, que foi quem fechou o diagnóstico. Aqui, percebe-se que o médico que inicialmente estava acompanhando a criança, sem ter a confirmação do diagnóstico, não a encaminhou para um tratamento precoce. Porém, como foi visto anteriormente, o médico já sabia que haveria sequelas. Kempinski ${ }^{17}$ diz em seu estudo que os critérios médicos para o encaminhamento de pacientes com disfunções neurológicas para atendimento fisioterapêutico estão relacionados à maior experiência clínica do médico, que reconhece a importância da fisioterapia por ter um maior contato com os resultados positivos da intervenção fisioterapêutica do que efetivamente pelo conhecimento científico dessa efetividade. Ao referir-se à reabilitação motora de uma criança, ou até mesmo às habilidades em geral, podemos afirmar que o fisioterapeuta se destaca, ao ser citado como o profissional mais requisitado para esse tipo de tratamento, delimitando a trajetória da criança no decorrer de sua vida, seja ela independente ou não no contexto familiar e social.

Após o encaminhamento, verificou-se que a maioria dos participantes referiu demora em iniciar o tratamento devido a situações de fragilidade da saúde da criança e do retardo na espera por vagas nos centros de reabilitação. Lima $^{29}$ destaca que quanto mais cedo forem as intervenções, melhores são os resultados em 
relação à criança com $\mathrm{PC}$ e ao mesmo tempo favorecem a adaptação da família, pois se revertem em uma maior segurança para lidar com as necessidades específicas. Porém, convém atentar que a adaptação das famílias e os melhores resultados estão relacionados, entre vários fatores, com a disponibilidade de suporte dos serviços sociais e de saúde. No caso dos pais participantes deste estudo a disponibilidade de vagas no serviço público de saúde influenciou em um tempo maior de espera para iniciar o tratamento.

Já em relação à atitude dos pais diante do encaminhamento do seu filho para a fisioterapia, foi visto que duas mães demonstraram maior dificuldade em entender e aceitar que o filho precisava iniciar o tratamento:

"Foi estranho (...) Só de saber que ela iria ter que fazer fisioterapia desde o começo do desenvolvimento foi bem difícil de aceitar" (P8, 26 anos)

Mesmo assim, todos os pais referiram sentimentos de esperança e de melhora das condições do filho:

“(..) Eu vi a fisioterapia como algo que fosse ajudar ele a evoluir melhor, comecei a ver o lado positivos das coisas, a acreditar que ele ia conseguir ficar bom (...)" (P6, 35 anos).

A opção por incluir a criança no tratamento abriu a possibilidade para os pais amadurecerem 0 seu conhecimento, obterem orientações e mais esclarecimentos quanto à deficiência do filho, o que mostra o quanto o fisioterapeuta deve desempenhar com responsabilidade o seu trabalho com a criança e seus familiares. O desejo de dar ao filho a oportunidade de desenvolver suas possibilidades faz com que os pais saiam em busca de tratamentos, reabilitação, entre outros recursos, na certeza de estar fazendo o que deve ser feito ${ }^{13}$. Em geral, o investimento na reabilitação dos filhos é diretamente influenciado pelas expectativas dos pais de uma possível melhora voltada às condições motoras, assim como coordenação e, principalmente, ao andar $^{23}$.

Estimando que a média de tempo do tratamento das crianças incluídas nesta pesquisa é de 3,5 anos, procurou-se saber dos pais quais eram as suas expectativas em relação à fisioterapia atualmente. Foi constatado que os pais esperam que o filho possa evoluir, mas dentro das condições que ele apresenta. Inclusive quatro pais falaram não esperar milagres na reabilitação da criança:

"Eu tenho consciência que ela tem limitações, não dá pra ficar se iludindo, pensando que vai acontecer um milagre. Pra mim as coisas estão bem. Eu sei que o processo é lento" (P1, 48 anos).

Há pais que também colocaram que esperam que o tratamento possa manter a qualidade de vida dos filhos:

"Eu sei que pela idade dele a maioria das coisas que ele podia fazer pra ganhar, já fez. Agora é praticamente manter a qualidade de vida" (P5, 37 anos).

À medida que o tempo de reabilitação avança e que algumas metas sonhadas, não são atingidas, os pais confrontam-se com a necessidade crescente de continuarem criando perspectivas de futuro para seu filho de uma forma diferente ${ }^{6}$. Diante disso, cabe conhecer como os pais participam do tratamento do filho e que tipo de relação eles estabeleceram com o fisioterapeuta. Assim, observou-se que todas as mães estão sempre presentes nas sessões de fisioterapia e que procuram acompanhar o tratamento. $O$ pai participante relatou que acompanha quando pode, mas procura sempre saber o que está acontecendo por intermédio da esposa.

Quanto ao relacionamento com o fisioterapeuta todos os participantes afirmam manter uma boa convivência com o profissional e confirmam a importância da proximidade deste:

"A vida da minha filha depende de mim e pra isso eu dependo de outras pessoas pra me ajudarem. Se ela evoluir é porque eu a trouxe até o fisioterapeuta, porque nós trabalhamos juntos (...)" (P7, 35 anos).

A presença dos pais e sua participação no tratamento 
de seus filhos têm como principal objetivo a continuidade e a manutenção da preservação dos resultados desejados no tratamento em nível domiciliar, além de estimular a interação entre os pais e o filho. Além disso, o estabelecimento de uma relação de confiança mútua e de parceria entre pais e profissionais é essencial para o melhor desenvolvimento da criança, pois, os pais, embora leigos, convivem por muito mais tempo com a criança e podem trazer dados importantes para serem trabalhados na sessão de fisioterapia ${ }^{30}$.

Quanto às mudanças que os pais observam no filho depois de ter iniciado a fisioterapia, foi visto que todos conseguem visualizar progressos:

"Ele é mais independente. Melhorou muito. Antes ele não conseguia nem sentar sozinho, caía para o lado. Agora ele já senta, ajuda a se vestir, consegue pegar as coisas, comer e tá aprendendo a caminhar" (P3, 34 anos).

Em um estudo realizado pelos autores Sari \& Marcon ${ }^{31}$ com mães, também foi visto que a maioria das entrevistadas (96\%) afirmou perceber resultados positivos após iniciar o tratamento de fisioterapia.

Com a adesão ao tratamento de fisioterapia os pais também comentaram sobre alterações de condutas na rotina familiar, adotando medidas diferentes para auxiliar o filho, passando a fazer tudo com o intuito de estimular a criança:

“O meu filho tinha um problema forte de visão (...). Daí a gente aprendeu a fazer estimulação visual, com cores, lanterna colorida e brinquedos coloridos. Hoje ele consegue enxergar melhor um objeto e direcionar a mão pra ele." (P4, 39 anos)

Também no estudo de Sari \& Marcon ${ }^{31}$ se observou que $96 \%$ dos entrevistados relataram estimular as crianças com conversas, músicas, brincadeiras, brinquedos sonoros e pedagógicos. Junto a isso, conversou-se a respeito das orientações que são passadas do profissional de fisioterapia para os familiares, sendo que todas as mães afirmaram receber orientações e que as realizam em casa.
A orientação dos profissionais é um recurso essencial para pacientes com determinados diagnósticos, principalmente quando estão relacionados à doença crônica, como a paralisia cerebral. A necessidade dos pais não está focada somente na capacidade, mas também nas vivências e sensibilidade dos profissionais. É preciso que estes se disponham a ouvir as dúvidas e preocupações dos pais, passando as informações com prudência e respeito ${ }^{16,18,32}$. Esse tipo de visão capacita o profissional a ser um bom orientador, podendo auxiliar os pais a entenderem melhor as particularidades da deficiência do filho e as possibilidades de progressão e limitação. Se os pais obtiverem a clareza desses aspectos, a sua participação no tratamento se tornará mais intensa e significativa. O fisioterapeuta deve conseguir mostrar o valor da continuidade do tratamento dentro do ambiente domiciliar.

\section{CONSIDERAÇÕES FINAIS}

Foi possível constatar que houve uma mudança na percepção do diagnóstico referente ao instante em que ele foi noticiado e o momento atual. Aquilo que inicialmente, pela maioria dos pais, foi envolto de angústia, incerteza e pífia compreensão da situação da criança com o passar do tempo passou a ser visto como algo menos obscuro, de melhor entendimento e aceitação. Essa transição de um extremo ao outro necessitou um esforço dos pais em buscar respostas, informações e adaptações no âmbito familiar. Ressaltase a importância do empenho da equipe interdisciplinar dos profissionais da saúde em fornecer o amparo indispensável para os pais e a criança com PC. O profissional precisa dispor-se a criar um vínculo, uma aproximação com os familiares da criança a fim de poder auxiliá-los de acordo com as necessidades que apresentarem.

Os participantes percebem o tratamento fisioterapêutico como uma condição pertinente, afirmando que observaram mudanças otimistas no desempenho do filho após iniciar a intervenção. A maioria enfatizou que sem 0 acompanhamento fisioterapêutico, o filho não conseguiria evoluir no mesmo nível. Dessa forma, o profissional da saúde deve ter conhecimento e estar preparado diante das 
perspectivas dos familiares. A qualidade na assistência dos serviços de saúde é primordial para um bom desenvolvimento da criança e uma adequada intervenção. Essa é a incumbência dos serviços de saúde e dos profissionais: procurar ampliar o olhar para a família e para a criança, não apenas para a patologia. Acredita-se que estudos buscando contemplar a percepção dos pais quanto à situação de seu filho e ao tratamento de fisioterapia contribuam para que esse tipo de comportamento possa ser efetivado.

\section{REFERÊNCIAS}

1. Mancini MC, Alves ACM, Schaper C, Figueiredo EM, Sampaio RF, Coelho ZAC, Tirado MGA. Gravidade da paralisia cerebral e desempenho funcional. Rev Bras Fisioter 2004; 8(1):253-60.

2. Zanini, G, Cemin NF, Peralles SN. Paralisia cerebral: causas e prevalências. Fisioter Mov. 2009; 22(3):375-81.

3. Martins LF, Pereira CA, Salgueiro C, Nogueira GP. Atuação fisioterápica após fenolização em pacientes com paralisia cerebral do tipo diparética espástica. Temas Desenvolv. 2005; 14(83/84):69-74.

4. Berker $\mathrm{N}$, Yalçin $\mathrm{S}$. The help guide to cerebral palsy. Istambul: Global-HELP Publication; 2005.

5. Miller F. Physical therapy of cerebral palsy. Wilmington: Springer; 2007.

6. Sousa SCB, Pires AAP. Comportamento materno em situação de risco: mães de crianças com paralisia cerebral. Psicol Saúde e Doenças 2003; 4(1):111-30.

7. Milbrath VM, Soares DC, Amestoy SC, Cecagno D, Siqueira $\mathrm{HCH}$. Mães vivenciando 0 diagnóstico da paralisia cerebral em seus filhos. Rev Gaúcha Enferm 2009a; 30(3):437-44.

8. Gração DC, Santos MGM. A percepção materna sobre a paralisia cerebral no cenário da orientação familiar. Fisioter Mov. 2008; 21(2):107-13.

9. Rotta NT. Paralisia cerebral, novas perspectivas terapêuticas. J Pediatr. 2002; 78(1):48-54.

10. Dantas MAS, Collet N, Moura FM, Torquato IMB. Impacto do diagnóstico de paralisia cerebral para a família. Texto Contexto Enferm. 2010; 19(2):229-37.

11. Goldim JR. Manual de iniciação à pesquisa em saúde. Porto Alegre: Da Casa; 2000.

12. Bardin L. Análise de conteúdo. Lisboa: Edições 70; 1995.

13. Barbosa MAM, Chaud MN, Gomes MMF. Vivências de mães com um filho deficiente: um estudo fenomenológico. Acta Paul Enferm 2008; 21(1):46-52.

14. Milbrath VM. Cuidado da família à criança portadora de paralisia cerebral nos três primeiros anos de vida.188 f. [Dissertação]. Rio Grande do Sul (RS): Universidade Federal do Rio Grande; 2008.

15. Lopes GB, Kato LS, Côrrea PRC. Os pais das crianças com deficiência: reflexões acerca da orientação em reabilitação motora. Psicol Teor Prát. 2002; 4(2):67-72.

16. Carvalho QCM, Maria VLMLC, Márcia MCO, Ingrid MLL. Malformação congênita: significado da experiência para os pais. Ciênc Cuid Saúde 2006; 5(3):389-97.
17. Kempinski EMBC. Percepção das famílias de crianças com Paralisia Cerebral: a fisioterapia e o processo de reabilitação contínua [dissertação]. Rio de Janeiro (RJ): Instituto de Medicina Social da Universidade do Estado do Rio de Janeiro; 2009.

18. Fonseca LF, Mariano SC. Humanizando o momento da notícia. In: Fonseca LF, Lima CLA. Paralisia cerebral: neurologia, ortopedia e reabilitação. Rio de Janeiro: Medbook; 2008.

19. Baird G, Conachie HMC, Scrutton D. Parents' perceptions of disclosure of the diagnosis of cerebral palsy. Arch Dis Child. 2000 Dec; 83(6):475-80.

20. Arruda DC, Marcon SS. Experiência da família ao conviver com sequelas decorrentes da prematuridade do filho. Rev Bras Enferm 2010; 63 (4): 595-602.

21. Bazon FVM, Campanelli EA, Blascovi-Assis SM. A importância da humanização profissional no diagnóstico das deficiências. Psicol Teor Prát. 2004; 6(2):89-99.

22. Falkenbach AP, Drexsler G, Werler V. A relação mãe/criança com deficiência: sentimentos e experiências. Ciênc Saúde Colet 2008; 13(1):2065-73

23. Sanches LAS, Fiamengui GAJ. Relatos maternos sobre o impacto do diagnóstico da deficiência dos filhos. Cad Saúde Coletiva 2011; 19(3):366-74.

24. Lervolino SA. Estudo das percepções, sentimentos e concepções para entender o luto de familiares de portadores da síndrome de Down da cidade de Sobral Ceará [tese]. São Paulo (SP): Faculdade de Saúde Pública; 2005.

25. Vieira NGB, Mendes NC, Frota LMCP, Frota MA. O Cotidiano de mães com crianças portadoras de paralisia cerebral. Rev Bras Promoç Saúde 2008; 21(001):55-60.

26. Roriz TMS. Inclusão/exclusão social e escolar de crianças com Paralisia Cerebral, sob a ótica dos profissionais da saúde [dissertação]. Ribeirão Preto (SP): Universidade de São Paulo; 2005

27. Souza ES. Participação e necessidade de assistência na realização de tarefas escolares em crianças com paralisia cerebral. Fisioter Mov. 2011; 24(3):409-17.

28. Miura RT. Experiências e qualidade de vida de mães de crianças com paralisia cerebral [dissertação]. Ribeirão Preto (SP): Universidade de São Paulo; 2007.

29. Lima DRG. Percepções e sentimentos dos cuidadores sobre a qualidade de vida de crianças menores de cinco anos com paralisia cerebral [dissertação]. Recife (PE): Instituto Materno Infantil Fernando Figueira; 2008.

30. Gondim KM, Pinheiro PNC, Carvalho ZMF. Participação das mães no tratamento dos filhos com paralisia cerebral. Rev Rene 2009; 10(4):136-44.

31. Sari FL, Marcon SS. Participação da família no trabalho fisioterapêutico em crianças com paralisia cerebral. Rev Bras Crescimento Desenvolv Hum. 2008; 18(3):229-39.

32. O'neil ME, Palisano R J. Attitudes toward family-centered care and clinical decision making in early intervention among physical therapists. Pediatr Phys Ther. 2000 Winter; 12(4):173-82.

\section{Endereço para correspondência:}

Clarissa Niederauer Leote da Silva Pedroso Avenida Inconfidência $n^{\circ} 81$

Canoas/RS - CEP 92025-403

Telefone: +55 5199277262

E-mail: cclarissa.fisioterapeuta@gmail.com 